\title{
DEVELOPMENTAL TOXICOLOGY - AN INTEGRAL PART OF SAFETY EVALUATION OF NEW DRUGS
}

\author{
Eduard Ujházyª, Mojmír Machª, Michal Dubovickýa, Jana Navarováa ${ }^{a}$ Ingrid Brucknerováb \\ ${ }^{a}$ Laboratory of Teratology, Institute of Experimental Pharmacology, Slovak Academy of Sciences, Bratislava, Slovakia \\ ${ }^{b} I^{\text {st }}$ Department of Paediatrics, School of Medicine, Comenius University, Bratislava, Slovakia \\ e-mail:exfaujha@savba.sk
}

Received: June 10, 2005; Accepted: September 25, 2005

Key words: Developmental toxicology/Teratology/Screening tests/Biomodels

The thalidomide tragedy stimulated an intense research in the etiology, prevention and treatment of congenital malformations. The Government requires that drugs and food additives be evaluated pre-clinically for toxicity, including developmental toxicity, before being marketed. The number of compounds which must be tested has increased dramatically with the continuous development of therapeutic, cosmetic and food additive chemicals. Such tests include: in vitro studies which can serve as efficient pre-screens to rank chemicals for further batteries of in vivo tests on pregnant animals. However, the safety of any drug would be determined only by a post-marketing epidemiological survey. Taking into account the altered susceptibility to different drugs in a pregnant individual, it could be said that administration of any drug during the first trimester is an experiment in human teratology.

\section{INTRODUCTION}

The aim of developmental toxicology is to detect any adverse effects of xenobiotics on the pregnant female and on the development of the embryo and foetus as a consequence to exposure from starting with implantation through the entire period of gestation, parturition and maturation. The very first events began in the early years of the $20^{\text {th }}$ century with experimentally-induced developmental toxicity in a mammal. In humans, the first exogenously caused (with pelvic X-irradiation) malformations were observed by Goldstein and Murphy ${ }^{1}$. In 1941 another important discovery was made. Gregg at al were first to reported virus-caused malformations in humans (eye defects due to rubella $)^{2}$. Actually, clinical proof that chemical agents can induce birth defects in the human species existed before the thalidomide disaster. Some 10 years earlier, the drug aminopterin, given in high abortifacient doses, caused multiple malformations in abortuses ${ }^{3}$. Assessment of the potential for developmental toxicity has been identified as one of the key areas to be considered in the evaluation of the safety of new drugs. The field opened up after the thalidomide controversy in the 1950s when the use of thalidomide by pregnant women to reduce the discomfort of pregnancy resulted in the appearance of many cases of birth defects, particularly in Germany. Before 1960, governmental recommendations given for testing chemicals during the reproductive cycle of animals were conventional 6 weeks chronic toxicity test in male and female rodents followed over two pregnancies. Foetal survival was the main parameter measured in this so-called litter test, the tests incapable of fully demonstrating toxicity to the embryo ${ }^{4}$. In response to the thalidomide tragedy, the Food and Drug Administration (FDA) and experts in the fields of reproduction and teratology issued Guidelines for Reproduction Studies for Safety Evaluation of Drugs for Human Use in 1966 (ref.5). The recommended tests were more comprehensive than the earlier ones; they specifically included testing during the teratogenic susceptibility stage of development. It has been estimated that more than 3300 chemicals have been tested for teratogenicity, with approximately $63 \%$ having been shown to be non-teratogenic, $7 \%$ teratogenic in more than one species, $21 \%$ teratogenic in most species tested, and $9 \%$ producing equivocal experimental results. In contrast, only about 35 chemicals, chemical classes, or conditions have been documented to alter prenatal development in humans ${ }^{6}$. A tabulation of all developmental toxicity classes of the agents considered human teratogens is shown in Table 1.

\section{MANIFESTATIONS OF DISRUPTIVE DEVELOPMENT}

We recognize four main manifestations or classes of deviant or disruptive development of the conceptus: malformations, growth retardations, embryolethality and functional impairment. The nature and incidence of developmental defects are dependent on the developmental stage insulted. This time period "the critical period of organogenesis" varies among the species and is partly dependent on the length of gestation (for e.g. degrees of susceptibility of embryonic organs to teratogens at different developmental periods in humans are depicted in Fig. 1). Other factors influencing severity of developmen- 
tal defects could be the route of administration, placental transfer, dose range and duration of treatment.

Malformations

They may be single or multiple (polymorphic). The initial teratogenic effect probably occurs through programmed cell death (apoptosis) or alteration in the rate of cell growth, but the final deformity represents not only the consequence of this direct injury, but also of secondary regenerative processes that follow it ${ }^{7,8}$. The pathogenesis of malformation can usually be shown to begin as one or more overt occurrences, such as cell death, reduced biosynthesis, impaired morphogenetic movement, failed tissue interaction, or mechanical disruption. Possible mechanisms for these events include mutation, chromosomal aberration, mitotic interference, altered nucleic acid or energy sources, biosynthetic imbalance, enzyme inhibition, osmolar imbalance, or altered membrane characteristics ${ }^{9}$.

\section{Growth Retardation}

Foetal size is an important parameter in the assessment of potential teratogens. Reduction in size or growth retardation commonly occurs among foetuses of dams given dosages that are toxic to the dam, to the offspring, or both ${ }^{10}$. Some investigators consider overall growth retardation is to constitute a state of increased susceptibility to congenital malformation ${ }^{11}$. Numerous agents are capable to cause intrauterine growth retardation (IUGR) (Table 1). The limit for IUGR in humans has been defined as birth weights less than $2500 \mathrm{~g}$ (ref. ${ }^{12}$ ).

\section{Embryolethality}

Death of offspring is another class of developmental toxicity. Mortality may primarily be due to the direct action of chemicals on the conceptus, regardless of whether they are coincidentally malformed or not, or it may be secondary to maternal effects, and it is difficult, if not impossible, to distinguish between the two ${ }^{13}$. When there is undue toxicity early in pregnancy in animals, the embryo dies, is resorbed, and only the presence of the site of implantation is indicated; its counterpart in the human is miscarriage, with the product usually expulsed from the uterus before the $20^{\text {th }}$ week.

\section{Functional Impairment}

Birth defects can affect anatomy as well as behaviour. Historically, the first publication to examine behavioural effects from the teratological perspective was published by Haddad et al. on prenatal administration of methylazoxymethano ${ }^{14}$. In recent years, increasing attention has been given to the more subtle, non-structural alterations produced by drugs and chemicals when given prenatally ${ }^{15}$. Examples for this kind of impairment may affect motor ability, sociability, emotionality, learning capacity etc. ${ }^{16}$.
Table 1. Developmental toxicity elicited by known human teratogens (Schardein, 2000) ${ }^{4}$

IUGR - Intrauterine Growth Retardation.

\begin{tabular}{|l|c|c|c|}
\hline \multicolumn{1}{|c|}{ Chemical } & IUGR & Death & $\begin{array}{c}\text { Functional } \\
\text { abnormality }\end{array}$ \\
\hline ACE inhibitors & + & + & - \\
\hline Alcohol & + & + & + \\
\hline $\begin{array}{l}\text { Aminoglycoside } \\
\text { antibiotics }\end{array}$ & - & - & - \\
\hline $\begin{array}{l}\text { Androgenic } \\
\text { hormones }\end{array}$ & - & - & - \\
\hline Anticancer agents & + & + & - \\
\hline Anticonvulsants & + & - & + \\
\hline Thyroid-active drugs & - & - & - \\
\hline Cocaine & + & + & + \\
\hline $\begin{array}{l}\text { Coumarin anatico- } \\
\text { agulants }\end{array}$ & + & + & + \\
\hline Diethylstilbestrol & - & + & - \\
\hline Lithium & - & + & - \\
\hline Methyl mercury & - & + & + \\
\hline PCBs & + & + & + \\
\hline Penicillamine & - & - & - \\
\hline Tetracycline & - & - & + \\
\hline Thalidomide & + & + & - \\
\hline Toluene & + & - & + \\
\hline $\begin{array}{l}\text { Hypervitaminosis A, } \\
\text { retinoid analogues }\end{array}$ & - & + & + \\
\hline
\end{tabular}

\section{TESTS FOR REPRODUCTIVE TOXICITY}

Adverse effects of chemicals on reproductive organs and function are detected by a variety of test methods ${ }^{17-19}$. The most direct measurement is made from fertility trials that are part of reproduction studies. Single or multiple generation reproduction studies, having typically one or two sets of litters per generation, are most often performed in mice, rats and rabbits. The safety assessment of new drugs and other chemical substances in terms of reproduction toxicity is conducted using a one-generation reproduction toxicity test ${ }^{20}$, which consists of three separate segments (Fig. 2):

- Segment I - Study of fertility and general changes during reproduction

- Segment II - Teratology study (selective embryotoxicity)

- Segment III - Perinatal and postnatal toxicological study.

These classical procedures could be followed by alternative methods ${ }^{19,21}$. They are used as screening techniques for testing embryotoxic effects of the substances on in- 


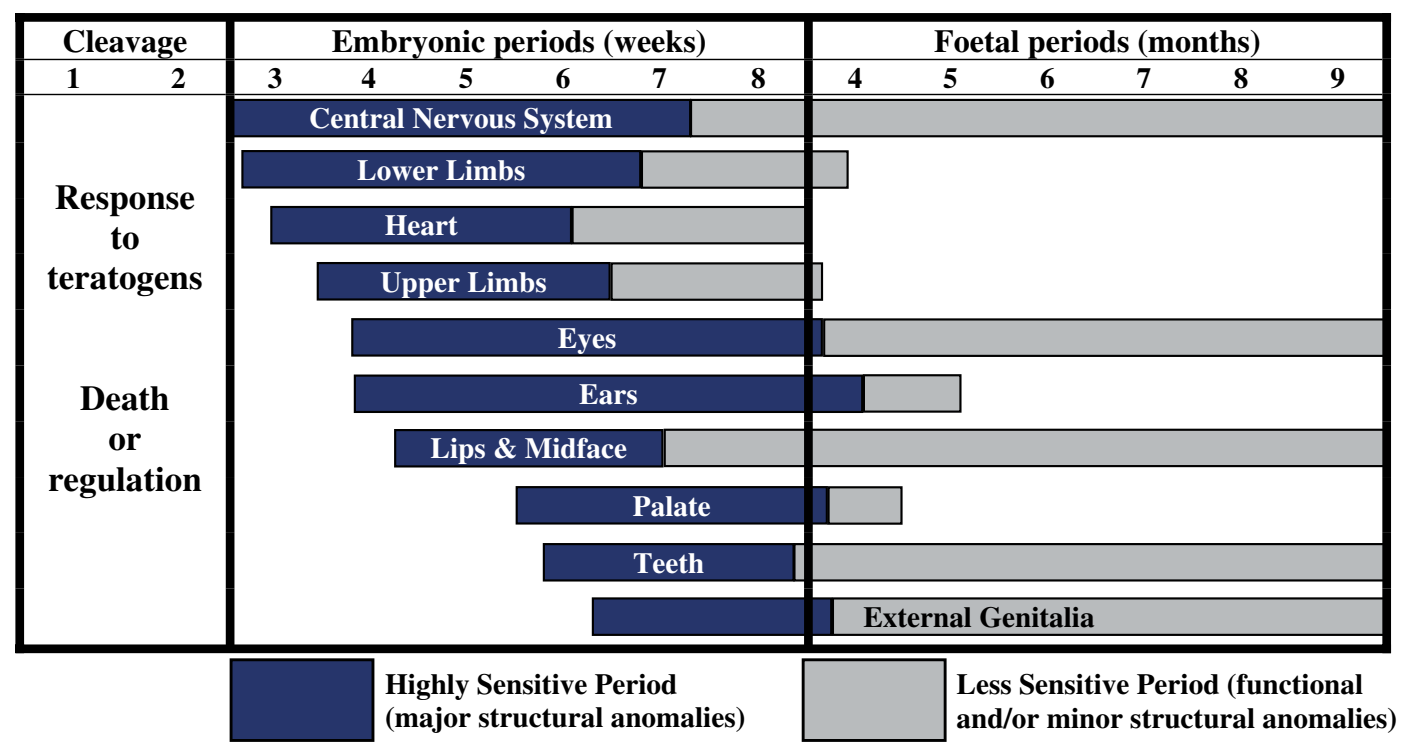

Fig. 1. Degrees of susceptibility of embryonic organs to teratogens at different developmental periods according to Wilson $(1973)^{9}$

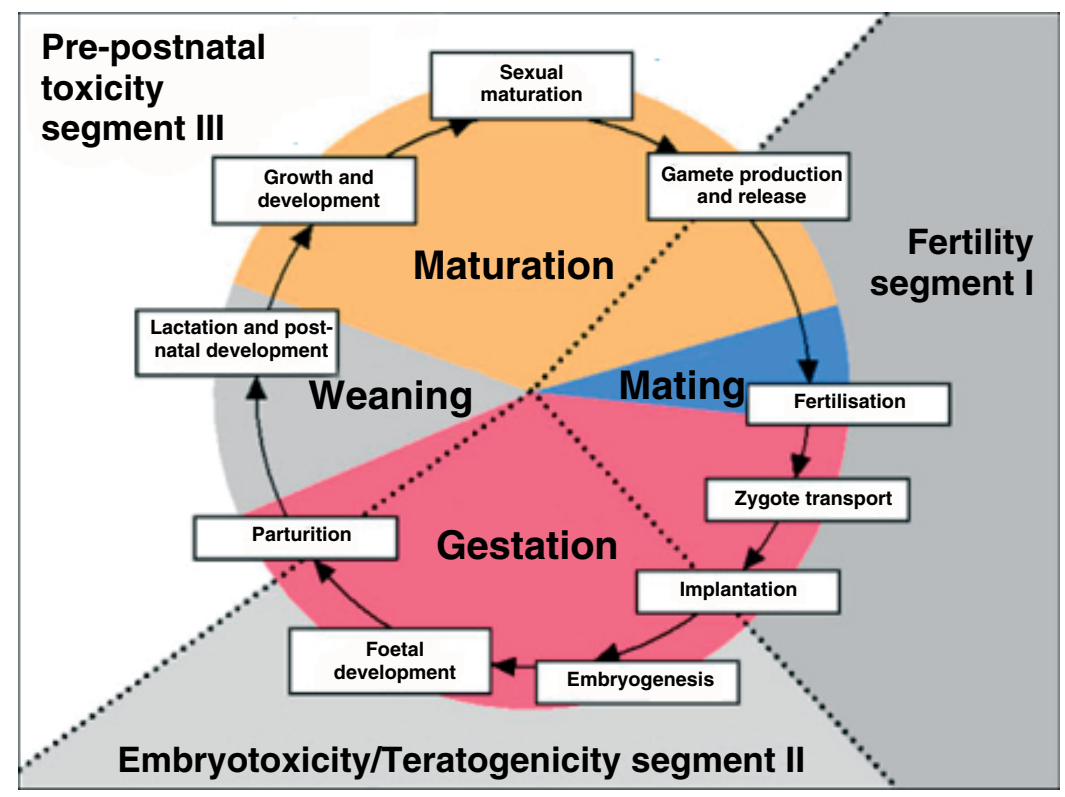

Fig. 2. Scheme of one-generation reproduction toxicity test (OECD, 1996) ${ }^{20}$.

tact non-mammalian embryos (Xenopus laevis, Drosophila melanogaster and Hydra attenuate). Among these, the Chick Embryotoxicity Screening test (CHEST) plays an important role ${ }^{22}$. Of the test systems in vitro whole mammalian embryo cultures and also organ and cell cultures have to be mentioned ${ }^{17,23}$.

\section{EXTRAPOLATION FROM ANIMALS TO HUMANS}

While developmental toxicants in humans produce similar responses in laboratory animals, animal studies are relatively ineffective at predicting the same type of response in humans ${ }^{4}$. Many mechanisms exist by which chemicals can cause birth defects, but the critical insult which accounts for the adverse effect on the embryo is known for only a few chemicals (Tab. 1). Although it has been possible in the mouse, rat and rabbit to demonstrate teratogenic activity by all substances that have been shown to be teratogenic in humans, there is no absolute assurance that negative results obtained by testing drugs in these species can be used to predict that an agent will lack teratogenic effects in humans. Similarly, it cannot be said that agents teratogenic in high doses in these species will necessarily produce teratogenic effects in humans at therapeutic dose levels ${ }^{24}$. It appears that different responses to 
xenobiotics in various species, including humans, result from interspecies differences in the kinetics and biotransformation of the agent based on different enzymatic and receptor equipments ${ }^{25}$.

\section{TERATOLOGY INFORMATION SERVICES}

Helping to prevent birth defects through education and research is the main goal of several organizations grouped in teratology information services. In Europe it is ENTIS (European Network of Teratology Information Services) helping in 16 countries, including the Czech Republic. In the USA, U.K. and Israel it is OTIS (Organization of Teratology Information Services). Teratology Information Services (TIS) are comprehensive and multidisciplinary resources for medical consultation on prenatal exposures. TIS interpret information regarding known and potential reproductive risks into risk assessments that are communicated to individuals of reproductive age and health care providers.

\section{CONCLUSIONS}

The reliability and extent of testing depends on the methods and experiences of the laboratory where the tests are performed. The current methodology derived from basic developmental toxicology research is able to detect the detrimental potential of the majority of substances, to identify the dose range of embryotoxicity and to determine the relationship between the dose and the effect. However, precise extrapolation will require not only knowledge of the specificity of the human xenobiotic metabolites but also the identification of the sensibility of the morphogenetic systems and their distribution in the time horizon of the development of the human embryo ${ }^{26}$. Finally, safety of any drug would be determined only by the post- marketing epidemiological survey.

\section{ACKNOWLEDGEMENT}

This work was supported by the grant from VEGA 2/5052/25 and APVT-20-02802.

\section{REFERENCES}

1. Goldstein L, Murphy DP. (1921) Etiology of ill-health in children born after maternal pelvic irradiation.II. Defective children born after postconception pelvic irradiation. Amer J Roentgenol Radium Ther Nucl Med 22, 322-31.
2. McAlister Gregg N. (1941) Congenital cataract following German measles in the mother. Trans Opthalmol Soc Aust 3, 35-41.

3. Tiersch JB. (1952) Therapeutic abortions with folic acid antagonist 4-aminopteroil-glutamic acid (4-amino P.G.A.) administered by oral route. Amer J Obstet Gynecol 63, 1298-1304.

4. Schardein LS. Chemically induced birth defects (Third edition). New York, Basel: Marcel Dekker, 2000.

5. Goldenthal E. Drug rewiew branch division of toxicological evaluation. Bureau of science, FDA, March 1966.

6. Rogers JM, Kavlock RJ. Developmental toxicology. In: Klaassen CD, Watkins III JB, editors. Casarett and Doull's toxicology. The basic science of poisons (Fifth edition). New York: McGraw-Hill Companies, 1999. p. 218-44.

7. Wilson JG. (1959) Experimental studies on congenital malformations. J Chronic Dis 10, 111-30.

8. Haring OM, Lewis FJ. (1959) Collective rewiew: The etiology developmental anomalies. Int Abst Surg 113, 1-18.

9. Wilson JG. Environment and birth defects. New York: Academic Press, 1973.

10. Ujházy E, Dubovický M, Mach M, Juránek I, Navarová J, Sadloňová I, Gajdošík A. (2000) Effect of phenytoin on prenatal and postnatal development of rats. Biologia 55 Suppl. 8, 125-30.

11. Spiers PS. (1982) Does growth retardation predispose the fetus to congenital malformation. Lancet 2, 312-4.

12. Miller HC. (1981) Intrauterine growth retardation. An unmet challege. Am J Dis Child 135, 944-8.

13. Kalter $H$. The relation between congenital malformation and prenatal mortality in experimental animals. In: Porter IH, Hook EB, editors. Human Embryonic and Fetal Death. New York: Academic Press, 1980. p 29-44.

14. Haddad RK, Rabe A, Laquer GL, Spatz M, Valcamis MP. (1969) Intellectual deficit associated with transplacentally induced microcephaly in the rat. Science 163, 88-90

15. Mach M, Ujházy E, Dubovický M, Navarová J, Blažiček P, Šoltés L. (2001) Structural and functional changes in rat offspring induced by prenatal phenytoin administration. Medical Military Letters 70, 79-82.

16. Dubovický M, Ujházy E, Kovačovský P, Rychlik I, Navarová J, Janšák J. (1999) Antioxidant stobadine and neurobehavioural development of the rat offspring. Gen Physiol Biophys 18, 41-7.

17. Neubert D, Merker HJ, Kwasigroch G. Methods in prenatal toxicology. Stuttgart: G. Thieme, 1977.

18. Hayes AW. Principles and Methods of Toxicology, Second Edition. New York: Raven Press, 1989.

19. Kotwani A, Mehta VL, Gupta U, Prabhu S, Bapna JS. (1995) Methods for teratogenicity testing-existing and future models. Ind J Pharmacol 27, 204-13.

20. OECD Guideline for testing of chemicals. 422, March 1996

21. Daston GP, D'Amato RA. (1989) In vitro techniques in teratology. Toxicol Ind Health. 5, 555-85.

22. Jelínek R. The chick embryotoxicity screening test (CHEST). In: Neubert D, Merker HJ, Kwasigroch G, editors. Methods in prenatal toxicology. Stuttgart: G. Thieme, 1977. p. 381-6.

23. Faustman EM. (1988) Short-term tests for teratogens. Mutat Res 205, 355-84

24. WHO. Guidelines for evaluation of drugs for use in man. Report of a WHO scientific group. (1975) World Health Organ Tech Rep Ser 563, 1-59.

25. Benešová O. (1982) Problems in extrapolating experimental data from animal to man. Čas Lék Česk 34-35, 1057-61.

26. Jelínek R. (1982) Extrapolace dat v teratologii. Čas Lék Česk 121, 1099-1102. 